\title{
Toward adaptive modelling \& simulation for IMS: The Adaptive Capability Maturity Model and future challenges
}

\author{
H.Bril El Haouzi, A.Thomas, P. Charpentier \\ CRAN, Université de Lorraine, CNRS, Campus scientifique \\ B.P. 70239 F-54506 Vandœuvre-lès-Nancy Cedex, France \\ (e-mail: \{hind.el-haouzi; andre.thomas; patrick.charpentier\}@univ-lorraine.fr).
}

\begin{abstract}
This paper intends to provide an overview of the design approaches of simulation and modelling in Intelligent Manufacturing System (IMS) context. We focus on adaptive capability of the simulation models pushed by the introduction of new paradigms, i.e. intelligent product and Internet of Things. A Capability Maturity Model will be proposed for adaptive capability assessment and will be illustrated from our past researches. We will conclude discussing a set of challenging prospects.
\end{abstract}

Keywords: Dynamic modelling and simulation, Data Driven Simulation, Intelligent Manufacturing System, Adaptive Capability, Maturity Model

\section{INTRODUCTION}

Since the 1990's, the production strategy in enterprises has changed from the traditional Mass production strategy (led by products) into the Mass Customization one (led by customers) in order to cope with the increasing global market competition. This change of approach is extremely challenging for control management and manufacturing system.

New visions for manufactured goods tend to give them communication and sensory ability within the framework of the intelligent product paradigm. This paradigm can be extended to a new conceptual framework "Internet of Things" (IoT). The aim of IoT is embedding real world information into networks, services and applications by using enabling technologies like wireless sensor and actuator networks, IoT devices, ubiquitous device assemblies and RFID (Strategic research Roadmap, 2009). Due to the increasing value of information created by the number of interconnection, smart items will be able to instruct their environment, to analyse their observations and to communicate with other objects and the Internet.

Even if efforts are made by scientifics and by industrial companies to promote those concepts, the deployment of these new paradigm are still considered challenging and suffer from low credibility and assessment strategy.

Historically, in order to evaluate the new approaches and to compare different production organizations, the simulation modelling is widely used. Simulation is a practical methodology for understanding the high-level dynamics of a complex manufacturing system (Law and Kelton, 1991). While simulation has much strength, there are some limitations for evaluation of several control policies, without a complete simulation model redesign. We need an underlying modelling discipline (or structured approach) for reduce time and efforts in simulation model maintenance and adaptation and provide genuine sustainability of developed simulation models. Those needs are reinforced and become critical especially in Intelligent manufacturing context, where the control management system is continually adapted from shop floor observations. The aim of this paper is: i) To show some researches findings in modelling \& simulation approaches and technics in IMS context and their assessment through a proposed Adaptive Capability Maturity Model (ACMM) and ii) To highlight challenges and future trends for modelling and simulation in this context.

Section 2 is dedicated to the presentation of existing literature on approaches for design of adaptive simulation model in manufacturing systems. Section 3 and 4 show our proposal for assessing the level of maturity of simulation models to be adaptive. The aspects of adaptive capability and their characteristics will also be detailed. The section 5 aims to illustrated the use of this model through our experiences in C.R.A.N Laboratory. The last section will be dedicated to challenges and future trends.

\section{STATE OF THE ART}

\subsection{Simulation \& modelling process}

In manufacturing, as in most of the application areas, a simulation is very often handmade by experts. A discussion about the model formulation time began with (T.R Willemain, 1995) and it is still on going. Simulation is not only modelling, but it is also studied as a rational process. The proposed methodologies for simulation have not changed in essence over several years (J. Banks and J.S Carson, 1988) (R. Kittell and A.Dunkin, 1991) (A.Maria, 1997) (J.Ryan and C.Heavey, 2006). A scheme that collects the commonly used steps is showed in Fig. 1. Each column shows the more important steps: Modelling, Scenarios and Analysis A. Vejar. et al., 2011). 


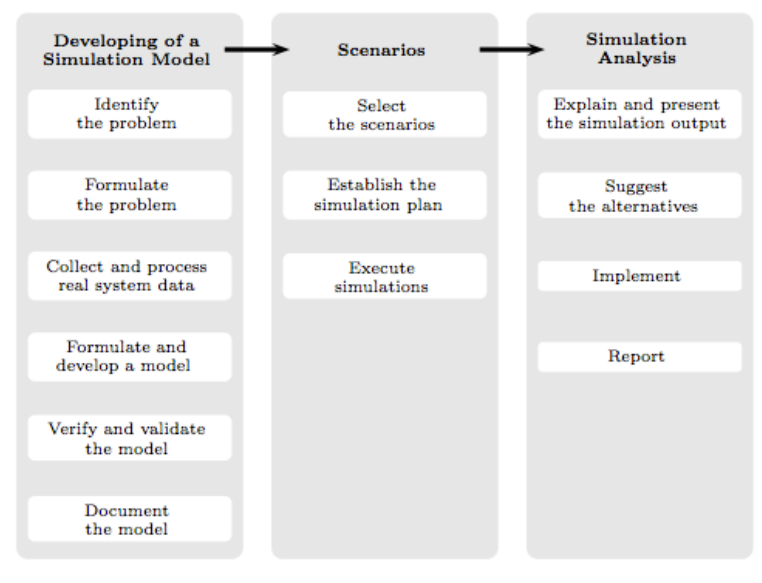

Fig. 1. Manufacturing simulation process.

\subsection{Simulation \& modelling approaches}

We can identify from the literature 3 major research and industrial approaches that share the aim of reducing time spent for design and adaptation works:

- $\quad$ Generic- or Template-based Simulation (GTS).

- Data-Driven Simulation (DDS).

\section{- Dynamic Data Driven Simulation (DDDS)}

A GTS modelling approach is used for an available set of pre-built modelling objects of common simulation situations. These modelling objects can be simply customized to fit the current application by "switching on" or "switching off" the generic object parameters (A.Guru et al,, 2004). An important advantage of GTS is model reuse as discussed in (M.J Steele, 2002) In (Y.J Son et al, 2000) the use of neutral libraries can expand the scope of applications of the GTS. Some authors (e.g. (S. Kasputis et al, 2000)) also talk about composable simulation, because the modelling process can be reduced to a simulation block composition. Today, most of generalpurpose simulation languages (such as Arena, Witness, Flexsim, and others) adopt this approach and many of them still provide very useful results for decision-making. Numerous papers and books on applications of these languages have been published. For Example Arena allows companies to create templates and libraries for their own particular processes. PSA Peugeot Citroen Company has developed a platform named MUSE, composed by a set of parametric templates in order to model the physical and logical behavior of assembly plants as presented by (A.Villeminot, 2004). Trane Company developed some years ago templates for Demand Flow Technology (DFT) processes used for different purposes, e.g. validate investments or design a product control system (H. El Haouzi et al, 2009).

In DDS, the model is generated automatically on the basis of existing data in the company databases. The model is updated when the data is changed. This approach differs from the traditional simulation approaches, because the human expert analyses the problem and defines each step of the simulation model generally using a GTS tool (Bing Cao, 2004). In the manufacturing system context, many papers and research studies promote the use of data imported from ERP system, MES, CAPP system or directly from sensors in order to design and/or maintain these simulation models. The major of those contributions were for off-line simulation.

In the context of on-line simulation, a new paradigm has appeared: Dynamic data driven simulation (DDDS). The principle is that simulation system is continually influenced by real time data for better analysis and prediction. The applications that it is possible to find in the literature deal with the older models used to make predictions about physical systems (i.e. weather forecasting, oil exploration, etc). However, the maturity of the concept is due to (Darema, 2004) who introduced "dynamic" DDS systems. The simulation applications can be able to accept new data during execution time and to extend the measurement process to be controlled dynamically by the application. (Yang, 2008) uses DDDS to build an inventory model, and (Kennedy, 2005) used DDDS for policy decision support. This approach is suitable for large data context (e.g. IoT, Intelligent manufacturing product) but still faced to many challenges that we will describe in section 5 .

\subsection{Simulation \& modelling capabilities}

Over the last two decades, the application of Modelling and Simulation to complex systems has demonstrated a number of capabilities that are crucial to large-scale use in industrial context.

The main effort in simulation community was about reusability issues; lots of papers focusing on it appear in major conferences and journals (Sargent, 1986)) (Wyatt, 1990). (S. Robinson et al 2004) gave a definition to the term "Simulation model reuse": they highlight the motivation of developing reusable models and the validity, the cost and credibility of reusability. A GTS approach is a good example for illustrating this ability. The aim is the capitalization of generic knowledge about simulation models of systems that have common properties, instead of studying every system and developing specific components.

Another ability widely studied is the modularity. In software development the modularity refers to the encapsulation of key sub-systems, objects and components behind welldefined and relatively stable interfaces. This facilitates the integration of these components with multiple applications, as well as the evolution or possible re-implementation of these components with minimal impact on the applications that use them. In the area of system modelling, modularity is used to improve system understanding, to reduce the model complexity, and to facilitate the reuse of standardized components. For example, systemic view subdivides the manufacturing system in three main subsystems: the physical factory subsystem, the informational subsystem (called logical subsystem in some simulation methodologies) and the decisional subsystem (Le Moigne, 1992). This vision deals with DDS as the information system feeding the simulation model of manufacturing system with relevant data. (El Haouzi et al, 2008) shows many persistent object-oriented 
methodologies for manufacturing simulation \& modelling and their contribution on reuse and modularity. Authors propose their own contribution in the context of intelligent product.

In modelling and simulation domain, and in particular, in IMS context, the property of adaptation was discussed in many past works. We can distinguish two different approaches: on-line simulation (e.g. DDDS) and off-line one (e.g. DDS).

Concerning the on-line approaches, the adaptation ability was studied mainly from adaptive behavior of some entities in the model or by changing the input variables of the model based on observations. In this way, (Pannequin et al, 2012) proposed a bio-inspired approach (e.g stigmergic models) to manage the agent's community and to induce a sort of selfadaptive simulation model. Agent-based models consider the abilities of complex adaptive system to evolve and to adapt as a collective result of the modifications occurring in the relational networks of agents. (Cardin, 2007) proposed to change some parameters on-line without a complete restructuration of model elements. The adaptation was made using another simulation model for observations and dissemination data into the first one. This kind of approach naturally leads to proactive simulation. (A.Vejar et al., 2011) have proposed an original method for the automatic generation of simulation models for discrete event systems. He used the product location data in the running system. The data stream of points (product identification, location, and time) is the input for an algorithm that generates a queuing network simulation model for a job shop system class. The modelling process has two main advantages: i) it does not require a priori knowledge about the system to model, and ii) the construction and updating of the model is performed online. Moreover, the resulting model type is "gray box": it does not dependent on its subsequent use, and it is at any time faithful to the reality due to the on-line collection and processing stages.

In off-line simulation, some authors highlight the issue with adapting a simulation model for complex system and preconize reduction methods for large-scale systems (SMR) to speed run-time. Amongst various authors, Zeigler was the first to deal with this problem (Zeigler BP., 1976). He distinguished four ways for simplifying a discrete simulation model. Doing so it is possible to replace a part of the model by a random variable, coarsening the range of values taken by a variable and grouping parts of a model together. He first listed 17 simplification techniques for general modelling. His four steps approach was: hypotheses (identifying the important parts of the system), formulation (specifying the model), coding (building the model) and experiments. (Brooks et al, 2000) suggest a "simplification of models" approach for those cases in which the indicators to be followed are the average throughput rates. But their work is no useful for following the various events taking place on the work center (WC). (Thomas et al, 2011) proposed a similar methodology, which maximize the bottleneck utilization rate and aggregate all the other WC in "macro-blocs". In another work, they proposed to reduce the simulation model, or to automatically generate it, thanks to a neuron network obtained by learning procedures.

Despite of a rich literature in the field of adaptability, there is no consensus about the definition of adaptive capability and expectations from Modelling and Simulation models. The purpose of following sections is to give a definition or a framework of adaptive ability and a Capability Maturity Model.

\section{Adaptive Capability and CMM FRAMEWORK}

\subsection{Adaptive capability}

The adaptation is the ability to modify the system state according to the environment changes. In reality this ability cannot be dissociated from another one, which is the evolution. The evolution is the ability of modifying the behavior, optimizing the response mechanisms to the environmental changes.

Table 1. Adaptive capacity at the local level:

\begin{tabular}{|c|c|c|}
\hline Characteristic & $\begin{array}{l}\text { Features that reflect } \\
\text { a high adaptive } \\
\text { capacity }\end{array}$ & $\begin{array}{l}\text { Illustrative elements from the } \\
\text { simulation \& modeling fields }\end{array}$ \\
\hline Assest base & $\begin{array}{l}\text { Availability of key } \\
\text { assets that allow the } \\
\text { system to respond to } \\
\text { evolving } \\
\text { circumstances }\end{array}$ & $\begin{array}{l}\text { C: The combination of artifacts, } \\
\text { objects, models, data, expertise, } \\
\text { ontologies } \\
\text { O:Mechanisms and tools allowing } \\
\text { the interplay of appropriate assets to } \\
\text { the changes } \\
\text { T:Ressources management, queuing } \\
\text { network }\end{array}$ \\
\hline $\begin{array}{l}\text { Institutions and } \\
\text { entitlements }\end{array}$ & $\begin{array}{l}\text { Existence of an } \\
\text { appropriate and } \\
\text { evolving institutional } \\
\text { environment that } \\
\text { allows fair access and } \\
\text { entitlement to key } \\
\text { assets and capitals }\end{array}$ & $\begin{array}{l}\text { C: Guidelines, methodological } \\
\text { approaches, standards. } \\
\text { O: Interoperability mechanism that } \\
\text { ensure access and entitlement to key } \\
\text { asset or resources } \\
\text { T: Mapping tools, assesments } \\
\text { frameworks }\end{array}$ \\
\hline $\begin{array}{l}\text { Knowledge and } \\
\text { information }\end{array}$ & $\begin{array}{l}\text { The system has the } \\
\text { ability to collect, } \\
\text { analyse and } \\
\text { disseminate } \\
\text { knowledge and } \\
\text { information in support } \\
\text { of adaption activities }\end{array}$ & $\begin{array}{l}\text { C: Meta-models and ontologies } \\
\text { O: Appropriate systems for data } \\
\text { gathering, informational analysis, } \\
\text { and dissemination } \\
\text { T: Database, System Expert, } \\
\text { Knowledge Modeling }\end{array}$ \\
\hline Innovation & $\begin{array}{l}\text { The system creates an } \\
\text { enabling environment } \\
\text { to foster innovation, } \\
\text { experimentation and } \\
\text { the ability to explore } \\
\text { niche solutions in } \\
\text { order to take } \\
\text { advantage of new } \\
\text { opportunities }\end{array}$ & $\begin{array}{l}\text { C: .Contunual imporvements } \\
\text { O:Dynamic Data Driven Simulation } \\
\text { T: Swarm intelligence, heuristics }\end{array}$ \\
\hline $\begin{array}{l}\text { Flexible forward- } \\
\text { looking decision- } \\
\text { making and } \\
\text { governance }\end{array}$ & $\begin{array}{l}\text { The system is able to } \\
\text { anticipate, incorporate } \\
\text { and respond to } \\
\text { changes with regards } \\
\text { to its governance } \\
\text { structures and future } \\
\text { planning }\end{array}$ & $\begin{array}{l}\text { C:Proactuve approaches } \\
\text { O:Plan actions } \\
\text { T:Real-Time monitoring }\end{array}$ \\
\hline
\end{tabular}


When we deal with this kind of capabilities, boundaries between social and artificial system tend to disappear. Today, lot of efforts and studies are made to adapt our social system to climate and economic changes within the sustainability framework. We chose to base our approach on the framework proposed by Overseas Development Institute (L. Jones et al, 2010) (Table 1), in order to analyze adaptive capacity at the local level in each country facing to climate changes. This framework identifies five interrelated characteristics that are conducive to adaptive capacity: the asset base, institutions and entitlements, knowledge and information, innovation, and flexible forward-looking decision-making. In table1, the first column presents the five key characteristics, the second column shows features that tend to support adaptive capacity and the last one provides some illustrative elements (conceptual, organizational and technical) and examples from modelling \& simulation standpoint.

\subsection{ACMM approach}

In the literature, there were lot of efforts to measure the maturity and credibility of software and hardware development processes and products. The best-known procedure is Capability Maturity Model (CMM). The CMM may be defined, according to the (CMMI report, 2002) as a model containing the essential elements of effective processes for one or more disciplines. It also describes an evolutionary improvement path from ad-hoc, immature processes to disciplined, mature processes, which result in improved quality and effectiveness. Over the last decade, some uses of CMM to M\&S field were presented but the focus was mainly on the validation $\&$ Verification processes or on predictive capability. Until now there is no reported works on adaptive capability definition and measurement in $\mathrm{M} \& \mathrm{~S}$.

\section{PROPOSED ACMM FRAMEWORK}

We propose a CMM to assess the maturity of a simulation model from the adaptive capability standpoint. We named this model ACMM). There are 2 major benefits from using it: i) to help to address challenges to move toward adaptive simulation model and ii) to track the effort for maturity progress.

The ACMM addresses four contributing elements to M\&S design: Data Management and Processing, Model Development, Model Validation, and Simulation Execution. For each of those elements, attributes are identified that characterize five increasing levels of maturity from different standpoints: conceptual, organisational and technical. In the following sections we will detailed the two axis of the ACMM: Elements contributing to M\&S process and the maturity levels and will give a matrix detailed key of challenges to move from a level to highest one.

\subsection{Elements or process categories contributing to M\&S process.}

In the modelling process shown in the state of the art (Fig 1): Certain phases of this process seem to be entirely the responsibility of the human expert. Others may be based, in part or totally, on methods that can be automated (Collect and Process Real System Data, Formulate and Develop a Model and Verify and Validate the Model). We consider those steps as the main elements contributing to $M \& S$ process within ACMM.

Data Management and processing: the objective is to collect and process real system data. Identify sources of randomness in the system (stochastic input variables). The questions from adaptive point of view will be: How data is collected, processed and updated? And how carefully accuracy is assessed?

Model development: in this step, the model is developed on the base of system knowledge and the collected data. At the same time or at the end of the development, the verification process ensures that developed models or components meet their specified requirements. In order to analyse the adaptive capability in this step, the question can be formulated as: Are the model and its components able to change or to be changed with a minimum effort?

Model validation: the purpose of validation process is to demonstrate that a product fulfils its intended use when it is placed in its intended environment. The issue here is the robustness of validation model. How carefully is the accuracy of the simulation and experimental results assessed in simulation model life cycle?

Simulation experiment: the aim of simulation is to make some changes in the input variables and to observe and to identify the reasons for change in the performance measures. The question here is how faster is time and frequency of updating model when the simulation is running and in which measure the simulation takes into account the real-time constraints"

\subsection{Maturity levels}

The maturity levels attempt to objectively track intellectual artifacts, or evidence, obtained in an assessment of adaptive capacity. The five maturity levels shown on (Fig. 2) provide the top-level structure of the ACMM.

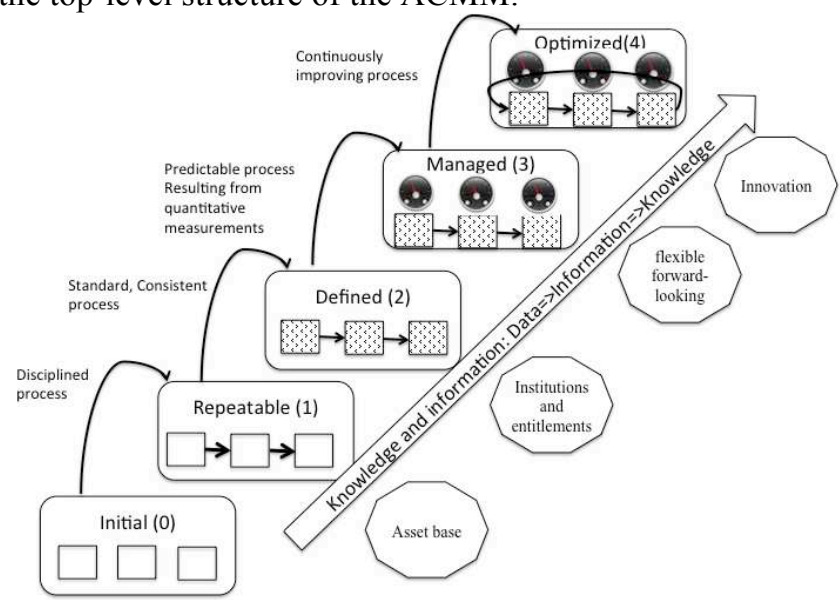

Fig 2: The Five Levels of M\&S Adaption Maturity 
Level 0: At the initial level there is no stable environment for developing and maintaining simulation model. Performance depends on the capabilities of individuals (experts) and varies with their innate skills, knowledge, and motivations.

Level 1: At the repeatable level, policies and procedures are established and used in case of new development or adaptation of the simulation models. This can help to better use of "asset base" that are knowledge, skills, etc.

Level 2: At the Defined Level, the standard process for developing and maintaining $M \& S$ models across the organization is defined and documented. Guidelines and approaches are proposed.

Level 3: At the Managed Level, the organization sets quantitative quality goals for $\mathrm{M} \& \mathrm{~S}$ models and its processes. Productivity (ex: time develop, to run simulation) and quality (confidence on model, data accuracy) are measured. The M\&S and processes can be summarized as predictable because the process is measured and operates within measurable limits. This level of process capability allows an organization to predict trends in M\&S models and processes quality within the quantitative bounds of these limits.

Level 4: At the Optimizing Level, the entire M\&S Processes are focused on continuous process improvement. The M\&S system has the aim to identify weaknesses and strengths in order to achieve better efficiency and effectiveness of adaptive models. The innovation is the main way leading to the optimization. Information and knowledge about innovation experience must be used and widely shared.

Table 2. General Descriptions for Table Entries of the ACMM

\begin{tabular}{|c|c|c|c|c|c|}
\hline $\begin{array}{l}\text { Maturity } \\
\text { lever, } \\
\text { Simulation Pracess } \\
\text { steps }\end{array}$ & $\begin{array}{l}\text { Level 0 } \\
\text { Intial }\end{array}$ & \begin{tabular}{|l} 
Level 1 \\
Repeatable
\end{tabular} & \begin{tabular}{|} 
Level 2 \\
Defined
\end{tabular} & \begin{tabular}{|l|l} 
Level 3 \\
Managed
\end{tabular} & \begin{tabular}{|l|l} 
Level 4 \\
Optimized
\end{tabular} \\
\hline $\begin{array}{l}\text { Data } \\
\text { Management and } \\
\text { Processing } \\
\text { How data is } \\
\text { collected, } \\
\text { processed and } \\
\text { updated, how } \\
\text { carefully accuracy } \\
\text { is assessed } \\
\end{array}$ & $\begin{array}{l}\text { C: Data not modeled, } \\
\text { heterogenous } \\
\text { representation, } \\
\text { occasional } \\
\text { modifications } \\
\text { O: Ad-hoc collecting and } \\
\text { storage systems } \\
\text { performed specially by } \\
\text { humain } \\
\text { T: Little or no updating } \\
\text { data, low accessibility }\end{array}$ & $\begin{array}{l}\text { C:Data are modelled in } \\
\text { rigid way } \\
\text { O:Collecting and storage } \\
\text { data systems procedures } \\
\text { and policies are known } \\
\text { T: closed data stprage } \\
\text { devices }\end{array}$ & $\begin{array}{c}\text { c: Ontologies or meta-model } \\
\text { are set } \\
\text { o: Data and their relations } \\
\text { are establish, standard for } \\
\text { maintenance are define } \\
\text { T: Standard processes and } \\
\text { documentation for } \\
\text { collectining, storing, and } \\
\text { updating data are defined } \\
\end{array}$ & \begin{tabular}{|c|} 
C: Process specification \\
for mapping and data \\
mangement \\
: Managed data \\
processing regarding \\
quantitative goals, \\
completness, accuracy, \\
objectivity \\
T: Efficience database (for \\
remote and quick access \\
to data)
\end{tabular} & \begin{tabular}{|c|} 
C: Moving from data to \\
knowidge dynamically, \\
met-models dynamically \\
adjust \\
O:Managing data life \\
cycle: dissemination, \\
destruction of old data \\
with horgotting factors.... \\
T: Automatic data \\
update, (batchs, \\
synchronization..), \\
Knowledge inferences
\end{tabular} \\
\hline $\begin{array}{l}\text { Model } \\
\text { Developement } \\
\text { Are the model and } \\
\text { its components } \\
\text { able to change or } \\
\text { to be changed } \\
\text { with a minumun } \\
\text { efforts }\end{array}$ & \begin{tabular}{|c} 
C:Fullyempirical \\
devlopement and \\
maintenance \\
O:Based only on \\
developers expertise \\
T: General purposes \\
languages, plattorm \\
dependant on process \\
modeling tools
\end{tabular} & $\begin{array}{l}\text { C: Semantic modelling } \\
\text { performed before } \\
\text { simulation models } \\
\text { developement stand- } \\
\text { alone models } \\
\text { 0:reusable components } \\
\text { and knowledges } \\
\text { T:Templates uses, } \\
\text { tracking of developement }\end{array}$ & $\begin{array}{c}\text { C: Methodological } \\
\text { approaches for } \\
\text { developement and } \\
\text { maintenance } \\
\text { o:Guidelines to develop, use } \\
\text { reusable components and } \\
\text { maintain or modify models } \\
\text { T: modularity, model } \\
\text { updated from database or } \\
\text { sensors }\end{array}$ & $\begin{array}{c}\text { C: modelling process is } \\
\text { able to anticipate, } \\
\text { incorporate and respond } \\
\text { to changes with regards to } \\
\text { standards and guidelines } \\
\text { O:Automatic generation } \\
\text { and update } \\
\text { (Time for developement } \\
\text { and maintenance } \\
\text { minimised); } \\
\text { T: instantiation, } \\
\text { particularization }\end{array}$ & $\begin{array}{c}\text { C: ability to explore niche } \\
\text { solutions in order to take } \\
\text { advantage of new } \\
\text { opportunities } \\
\text { O: Dynamic Data Driven } \\
\text { modelling, real-time } \\
\text { monitoring, swarm } \\
\text { algorithms } \\
\text { T: Distributed platforms } \\
\text { multi-agents platforms }\end{array}$ \\
\hline $\begin{array}{l}\text { Model Validation: } \\
\text { Robustness of } \\
\text { assessment } \\
\text { processs. How } \\
\text { carefully is the } \\
\text { accuracy of the } \\
\text { simulation and } \\
\text { experimental } \\
\text { results assessed } \\
\text { in simulation } \\
\text { model life cycle } \\
\end{array}$ & $\begin{array}{l}\text { C.Judgement only } \\
\text { O:No explicite } \\
\text { validation process } \\
\text { T: Benchmarking or } \\
\text { experts validation }\end{array}$ & $\begin{array}{l}\text { C: Policies and } \\
\text { procedures for validation } \\
\text { process are used } \\
\text { O: stand-alone validation } \\
\text { with experts } \\
\text { T:multiples } \\
\text { experimentations, } \\
\text { confidente intervals } \\
\end{array}$ & \begin{tabular}{|l|l} 
& \\
C:Standard validation \\
processes based on multiple \\
leves \\
O:hierarchical or iterative \\
approach for modelling \\
T:Generalization, and \\
particularization \\
\end{tabular} & $\begin{array}{l}\text { C: Robusness for } \\
\text { validation process is } \\
\text { garenteed } \\
\text { O: Comparison between } \\
\text { to simulation models } \\
\text { instances to induce } \\
\text { changes in validation } \\
\text { models } \\
\text { T: Statistical analysis } \\
\end{array}$ & $\begin{array}{l}\text { C: Adaptive model } \\
\text { validation process } \\
\text { O: Continual } \\
\text { assessement of } \\
\text { validation processes } \\
\text { T: Identify the critical } \\
\text { changes } \\
\end{array}$ \\
\hline \begin{tabular}{|l|} 
Simulations \\
Execution: \\
How faster is time \\
and frequencies of \\
updating model \\
when the \\
simulation is \\
running and in \\
which measure \\
the simulation \\
takes into account \\
the real-time \\
constraints" \\
\end{tabular} & $\begin{array}{l}\text { C: Basic simulation run } \\
\text { configurations } \\
\text { O: No management of } \\
\text { inputs } \\
\text { T: Handmade } \\
\text { interactions, no } \\
\text { structure of inputs } \\
\text { parameters }\end{array}$ & $\begin{array}{l}\text { C: simulations } \\
\text { experiments are known } \\
\text { o:Off-line inputs } \\
\text { variables changes } \\
\text { T:Stand-alone } \\
\text { modifications }\end{array}$ & $\begin{array}{l}\text { C: Simulation process: } \\
\text { senarios, inputs changes are } \\
\text { defined and documenetd } \\
\text { O: Rules and methods for } \\
\text { runs configuration and } \\
\text { reconfiguration are } \\
\text { proposed } \\
\text { T: Databases used, APIs for } \\
\text { multiple plattorms } \\
\text { connections } \\
\end{array}$ & \begin{tabular}{|l|} 
c:Dynamic \\
reconfiguration \\
O: Automatic inputs \\
modifications from \\
database: direct mapping \\
between objects \\
T: collaborative \\
execustion tools \\
\end{tabular} & $\begin{array}{l}\text { C: Dynamic simulation } \\
\text { processs reconfiguration } \\
\text { o: Real-time monitoring } \\
\text { of processes, adaptive } \\
\text { experimentation } \\
\text { senarios } \\
\text { T:Real Time } \\
\text { synchronisation Between } \\
\text { simulation models and } \\
\text { real sytem }\end{array}$ \\
\hline
\end{tabular}

\section{ASSESSMENT USING ACMM.}

In terms of illustration, we choose to present assessments of some of our past researches with ACMM. In (Vejar et al, 2011) contribution, data collection is done in real time on the process. Forgetting factors are set to consider only the meaningful information at time t. (DMP: 4). By nature, the model is automatically constructed. Against it is limited to one type of system and is not universal (queuing network). It has no ability to adapt to forthcoming system changes to be modeled (MD: 3). The generated model is validated if the generator is working properly. This validation is conducted on-line $(\mathrm{MV}: 4)$. Although there is a response time for the updating of the model by the generator, the model can be regarded as synchronized to the system of interest (SE: 4)

Works of (Pannequin et al, 2012) concern the product driven systems. This concept states that products are intelligent and can be represented by agents able to carry, disseminate and catch their own information (DMP: 3). Model changes are made automatically, with predefined scenarios (on-line approach). It is possible to consider that the agents behaviour is modify according to pre-established standards (MD:4). But the system is not able to validate itself its performance (MV: 3). Nevertheless and thanks to RFID, the coordination between agents and products is made in a near real time (SE: 4).

\section{CONCLUSIONS AND CHALLENGES.}

In this paper, we have shown a state of the art of the use of simulation models in IMS. We highlight the interest of adaptability ability in this context and for the new paradigms like IoT. We have then proposed a framework of adaptive ability characterization. An Adaptive Capability Maturity model based on CMM approach was also proposed. It should be considered as a basis and a starting point for further research and development. In terms of perspectives, several challenges have to be addressed in the future. First, we have to refine the proposed model and propose quantitative metrics and a structured approach for the model use. Second, the model has to be used on significant approaches on M\&S field from the literature. The aims are to open discussion and validate and improve the ACMM. Finally, we have to propose best practices to answer the challenges for adaptive modeling $\&$ simulation and move from a level to highest one. Future challenges form M\&S in the context of IMS would be, in the four described steps, achieving the level 4 of our framework.

\section{REFERENCES}

Internet of Things: Strategic Research Agenda, Septembe 2009. <http://ec.europa.eu/information_society/policy/rfi d/documents/ in_cerp.pdf $>$.

Law A. M., and. Kelton W. D., 1991. "Simulation Modeling \& Analysis", McGraw-Hill, 2e edition,

T R Willemain. (1995) Model Formulation: What Experts Think About and When. Operations Research, 43(6):916-932.

Jerry Banks and John S Carson II. Applying the simulation process. In WSC \{'\}88: Proceedings of the 20th 
conference on Winter simulation, pages 52-55, New York, NY, USA, 1988. ACM

Robert Kittell and Ann Dunkin. Applying the simulation process: simulation study of HDA parts degreaser. In WSC \{'\}91: Proceedings of the 23rd conference on Winter simulation, pages 816-821, Washington, DC, USA, 1991. IEEE Computer Society.

Anu Maria. Introduction to modeling and simulation. In Proceedings of the 1997 Winter Simulation Conference, pages 7-13, Washington, DC, USA, 1997. IEEE Computer Society.

John Ryan and Cathal Heavey. Process modeling for simulation. Computers in Industry, 2006.

A. Véjar and P. Charpentier, Generation of an Adaptive Simulation Driven by Product Trajec- tories. (to appear in) Journal of Intelligent Manufacturing, S.I : Intelligent \& Distributed Production Control. 2011.

Ashu Guru and Paul Savory. A Template-Based Conceptual Modeling Infrastructure for Simulation of Physical Security Systems. In R G Ingalls, M D Rossetti, J S Smith, and B A Peters, editors, WSC'04: Proceedings of the 36 th conference on Winter simulation, pages 866 873, 2004.

M J Steele, M M G Rabadi, and G Cates. Generic Simulation Models of Reusable Launch Vehicles. In Proceedings of the 2002 Winter Simulation Conference, pages 747-753, 2002.

Young Jun Son, Albert T Jones, and Richard A Wysk. Automatic Generation of Simulation Models From Neutral Libraries: An Example. In J A Joines, R R Barton, K Kang, and P A Fishwick, editors, WSC'00: Proceedings of the 32th conference on Winter simulation, pages 1558-1567, 2000.

S. Kasputis and H C Ng. Model Composability: Formulating a Research Thrust: Composable Simulations. In Proceedings of the 2000 Winter Sim- ulation Conference, pages 1577-1584, 2000.

H El Haouzi, A Thomas, JF Pétin (2008): Contribution to reusability and modularity of manufacturing systems simulation models: application to distributed control simulation within DFT context. International Journal of Production Economics 112 (1), 48-61

H El Haouzi, JF Pétin, A Thomas (2009): Design and validation of a product-driven control system based on a six sigma methodology and discrete event simulation Production Planning and Control 20 (6), 510-524 (2009)

Bing Cao, Richard Farr, Mike Byrne, and James Tannock 2004. Data-driven Simulation of the Extended Enterprise. 18th International Conference on Production Research.

F Darema. Dynamic Data Driven Applications Systems: A New Paradigm for Application Simulations and Measurements. In Proceeding of the 2004 International Conference on Computational Science, pages 662-669, 2004.

G M Clark and C R Cash. Data-driven simulation of networks with manuacturing blocking. In Proceedings of the 1993 Winter Simulation Conference, 1993.
Minghui Yang. Using data driven simulation to build inventory model. Proceedings of the 2008 Winter Simulation Conference, pages 2595-2599, 2008.

$\mathrm{C}$ Kennedy and $\mathrm{G}$ Theodoropoulos. Towards Intelligent Data-Driven Simu- lation for Policy Decision Support in the Social Sciences. Technical report, University of Birmingham, School of Computer Science, 2005

Sargent R.G., 1986. "Issues in simulation model integration, reusability, and adaptability", in: J.Wilson, J.Henriksen, S.Roberts (Eds.), Proceedings of the Winter Simulation Conference, Institute of Electrical Electronic Engineers, Piscataway, NJ, pp.512-516.

Wyatt D.L., 1990. "A framework for reusability using graphbased models", in:O. Balci, R.P. Sadowki, R.E. Nance (Eds), Proceeding of the 1990 Winter Simulation Conference, Institute of Electrical and Electronic Engineers, Piscataway, NJ, pp. 472-476

Le Moigne J.-L , 1992. “ La modélisation des systèmes complexes". Editions Dunod. A. Anglania, A. Griecoa, M.

Lindsey Jones, Eva Ludi and Simon Levine.Towards a characterisation of adaptive capacity (December 2010): a framework for analysing adaptive capacity at the local level Background Note. Overseas Development Institute

G.S.Innis and E.Rexstad - « Simulation model simplification techniques »- Simulation, $\mathrm{N}^{\circ} 41-\operatorname{Pg} 7-15-1983$.

R. J. Brooks and A. M. Tobias - «Simplification in the simulation of manufacturing systems » - IJPR Vol38 Pg 1009-1027-2000.

B.P. Zeigler - « Theory of modelling and simulation » - New York. Wiley - 1976.

R. Pannequin and A. Thomas, Another interpretation of stigmergy for product-driven systems architecture, Journal of Intelligent Manufacturing, (2012-00-00).

P. Thomas, A. Thomas, MC. Suhner, A neural network for the reduction of a Product Driven System emulation model, Production Planning \& Control, (2011-11-00).

Technical Report CMU/SEI-93-TR-025 ESC-TR-93-178. Key Practices of the Capability Maturity ModelSM, Version 1.1 Mark C. Paulk Charles V. Weber Suzanne M. Garcia Mary Beth Chrissis Marilyn Bush. February 1993

Villeminot A. : « Modélisation et simulation de la logistique d'approvisionnement dans l'industrie automobile: Application à un grand constructeur », $\mathrm{PhD}$ thesis, Nancy University, 2004 december 10.

Cardin O: (2007 thèse de doctorat: Apport de la simulation en ligne dans l'aide à la decision pour des systèmes de production Application à un système flexible de production 